\title{
HYDROGEN PRODUCTION FROM ALTERNATIVE AQUEOUS SOURCES: A FEASIBILITY STUDY
}

\author{
Solomon Giwa $^{1 *}$, Collins Nwaokocha ${ }^{1}$, Clement Ogunbona ${ }^{2}$, Oluwatobi Shittu $^{1}$ \\ ${ }^{1}$ Olabisi Onabanjo University, College of Engineering and Environmental Studies, Department of \\ Agricultural and Mechanical Engineering, Ibogun Campu, Ogun State, Nigeria. \\ ${ }^{2}$ Bells University of Technology, Department of Chemical Sciences, College of Natural Sciences, \\ Km. 8, Idiroko Road, Benja Village, P.M.B. 1015, Ota, Ogun State, Nigeria
}

(Received: December 2016 / Revised: March 2017 / Accepted: October 2017)

\begin{abstract}
This paper presents the production of hydrogen from various aqueous sources (de-ionized water, fufu effluent, sea water, run-off water, tap water, and urine). Two sets of hydrolysis experiments (with and without the dissolution of $\mathrm{NaCl}(35 \mathrm{~g} / \mathrm{l})$ into the aqueous media) were conducted using $12 \mathrm{~V}$ (DC supply) with graphite electrodes. The current utilized and volume of hydrogen produced was measured, while hydrogen flow rate, power, and effectiveness were estimated. The significance of the addition of $\mathrm{NaCl}$ to the aqueous media was analyzed using a $t$-test. It was observed that the dissolution of $\mathrm{NaCl}$ into the aqueous media had an appreciable effect on the values of $\mathrm{pH}$, volume and flow rate of hydrogen produced, current utilized, power consumed, and effectiveness compared to the values obtained without $\mathrm{NaCl}$ dissolution. This was corroborated by the result of the $t$-test $\left(\mathrm{t}_{\text {critcal }}(2.0452)<\mathrm{t}_{\text {observed }}(4.1139)\right.$ with a $p$-value of 0.0032 at $95 \%$ confidence interval), indicating the significance of the dissolution of $\mathrm{NaCl}$ into the media. The results showed that urine, followed by sea water, fufu effluent, run-off water, tap water, and de-ionized water, had the highest volume and flow rate of hydrogen, whereas the value of effectiveness was highest for de-ionized water, followed by tap water, sea water, urine, fufu effluent, and run-off water. Run-off water and fufu effluent were also demonstrated to be potential sources of hydrogen production outside urine and sea water.
\end{abstract}

Keywords: Hydrogen production; Power; Nigeria; Urine; Wastewater

\section{INTRODUCTION}

The health and environmental implications of burning fossil fuels are of global and local concern. Some disadvantages of fossil-based fuels include their significant contribution to global warming, which leads to climate change and has caused several natural disasters, extreme weather conditions, widespread diseases, ocean and sea level rise, etc.; their nonrenewable and unsustainable characteristics given the finite nature of existing reserves; and acid rain, which irritates the skin and destroys vegetation (Giwa et al., 2010; Saksono et al., 2015).

A key advantage of hydrogen $\left(\mathrm{H}_{2}\right)$ as an energy carrier is that carbon dioxide is not produced when it is burned, only water vapor. Apparently, $\mathrm{H}_{2}$ does not pollute and impact the environment negatively; hence, a "Green Environment" can be attained. $\mathrm{H}_{2}$ has the potential to run a fuel-cell engine with greater efficiency compared to an internal combustion engine

\footnotetext{
*Corresponding author's email: solomongiwa2002@yahoo.com,Tel: +234-810-604-8707, Fax: +234-810-604-8707 Permalink/DOI: https://doi.org/10.14716/ijtech.v8i5.869
} 
(Nasruddin et al., 2016a). With the use of an equal quantity of fuels, a fuel cell-car $\left(\mathrm{H}_{2}-\right.$ powered) will travel at least twice the distance as a gasoline-fueled car (Amoo \& Fagbenle, 2014).

$\mathrm{H}_{2}$ is a multipurpose energy carrier with the potential for widespread use in electricity generation for the institutional, industrial, residential, commercial, transportation, and agricultural sectors. $\mathrm{H}_{2}$ has almost three times the energy content as natural gas and produces environmentally friendly emissions upon combustion (Nasruddin et al., 2016b). $\mathrm{H}_{2}$, unlike oil and gas, is not a fuel but rather a medium for transporting energy. $\mathrm{H}_{2}$ can be produced from a variety of feedstocks. These include fossil resources (natural gas) as well as renewable resources (biomass and water) with input from renewable energy sources (wind, solar, wave, or hydro-power).

Various process technologies can be used for $\mathrm{H}_{2}$ production, including chemical, biological, electrolytic, photolytic, and thermo-chemical (Bouazizi et al., 2014; Holladay et al., 2009; Slamet et al., 2015). Local feedstock availability, the level of development of the technology, market demand, and costs and policy issues will largely determine the selection and timing of the different options for $\mathrm{H}_{2}$ production. Numerous feedstocks (methane from different sources, agricultural and municipal wastes), available on a geographical basis, can be explored for $\mathrm{H}_{2}$ production. However, electrolysis of water has been widely used for large-scale production of pure $\mathrm{H}_{2}$, especially from renewable sources, with about $5 \%$ of $\mathrm{H}_{2}$ produced from renewable sources (via electrolysis of water) and around 95\% synthesized from fossil fuels (through gasification, pyrolysis, steam reforming etc.) (Slamet et al., 2015). However, these processes are still intermediate technologies since they require a large amount of energy to produce $\mathrm{H}_{2}$ (Luo et al., 2009). For $\mathrm{H}_{2}$ to be a renewable energy carrier, it should be produced from renewable energy sources ( $\mathrm{Ni}$ et al., 2006). However, about $95 \%$ of $\mathrm{H}_{2}$ produced recently is from non-renewable sources, such as natural gas steam reforming ( $\mathrm{Ni}$ et al., 2006). Consequently, it is imperative to identify and develop feasible wastewater sources for practical, renewable $\mathrm{H}_{2}$ production.

Several chemicals, including hydrazine and metal hydrides, have been considered as promising $\mathrm{H}_{2}$ sources (Wang et al., 2012). Nevertheless, most of these are highly toxic, costly, and flammable; in addition, their supply is not sustainable (Wang et al., 2012). Societal need for alternative energy sources has motivated recent research on the utilization of wastewater as a useful fuel (Boggs et al., 2009). Several studies have investigated wastewater from various sources (milk water, kitchen water, urine, olive pucker water, etc.) for the production of $\mathrm{H}_{2}$ (Aggarwal et al., 2013; Boggs et al., 2009; Slama, 2013; Wang et al., 2012) with the aim of accomplishing fuel production and remediation of harmful compounds that currently pollute the environment (Boggs et al., 2009; Slama, 2013). Prominent among these studies was one in which $\mathrm{H}_{2}$ was produced from urine, as reported by other authors (Aggarwal et al., 2013; Boggs et al., 2009; Slama, 2013).

To the best of our knowledge, the literature on the production of $\mathrm{H}_{2}$ from any feedstock is scarce in Nigeria, although a recent study by Amoo and Fagbenle (2014) reported an assessment of the economic impact of $\mathrm{H}_{2}$ as a future energy carrier on the transportation, power, and energy sectors of the country. This paper presents for the first time the production of $\mathrm{H}_{2}$ from different aqueous sources. Thus, the aim of this study was to investigate the feasibility of $\mathrm{H}_{2}$ production from selected aqueous media (AM) using electrolysis. 


\section{MATERIALS AND METHODS}

\subsection{Materials, Apparatus, and Equipment}

This study focused on the production of $\mathrm{H}_{2}$ from selected AM using electrolysis. The AM investigated in this study were fufu effluent (FE), de-ionized water (DIW), sea water (SW), urine, run-off water (ROW), and tap water (TW). The SW was collected at Bar beach, Lagos Island, Lagos State, Nigeria, while the urine (early morning) was collected from the authors. The availability of these media in the immediate environment informed their selection for this study. The apparatus used for this study included an electrolytic chamber, common salt $(\mathrm{NaCl}$; 99\% pure), graphite electrodes, a collecting chamber, a burner, connecting tubes, a $12 \mathrm{~V}$ (DC) battery, and other glassware. The equipment utilized included a pH meter (model: $\mathrm{pH} 211$ ), an EC meter (model: HI 86303), and a salinity meter (model: HI 86303). These meters were all produced by Hanna Instruments, USA.

\subsection{Characterization of Aqueous Samples}

Prior to the electrolysis (hydrolysis) of the AM selected for the production of $\mathrm{H}_{2}$ in this study, the aforementioned media were tested for their $\mathrm{pH}$, resistivity, and salinity using the $\mathrm{pH}$ meter, EC meter, and salinity meter, respectively.

\subsection{Experimental Setup and Procedure}

The DIW was used as a control experiment as it contains no free ions that could affect the experimental results. Two sets of experiments were conducted without a change in the experimental setup. The first set of experiments was carried out without the addition of common salt $(\mathrm{NaCl})$ to the $\mathrm{AM}$; whereas the second set of experiments was conducted with the addition of $\mathrm{NaCl}$. This was done to investigate the effect of $\mathrm{NaCl}$ on $\mathrm{H}_{2}$ production from the AM. These experiments were run for a period of 30 mins. Common salt was used as an additive to reduce the activation energy of the hydrolyzed liquid and thus increase the production of $\mathrm{H}_{2}$. Common salt was also selected due to its availability and cost implication. The concentration of $\mathrm{NaCl}$ added to the $\mathrm{AM}$ was $35 \mathrm{~g} / \mathrm{l}$, as preliminary studies indicated that no significant improvement in $\mathrm{H}_{2}$ production was observed when less $\mathrm{NaCl}$ was added.

For the two sets of experiments, 1 litre of the various aqueous sources was electrolyzed in the electrolytic chamber by passing a $12 \mathrm{~V}$ direct current through it. Graphite electrodes were used as the anode and cathode of the experimental setup because they are cheap and readily available. Since $\mathrm{H}_{2}$ was produced at the cathode in this study, the cathode was keenly observed while activity at the anode was ignored. It is worth noting that the experiments were carried out under an ambient condition at room temperature $\left(27^{\circ} \mathrm{C}\right) . \mathrm{H}_{2}$ is naturally explosive at high pressures and temperatures and as such was not stored. The $\mathrm{H}_{2}$ produced was collected over water, and the volume of displaced water was measured as the volume of $\mathrm{H}_{2}$ produced based on Archimedes' Principle. This was achieved by filling the collection chamber to the brim with water prior to the commencement of the experiments. A connecting tube was used to supply the collection chamber with $\mathrm{H}_{2}$, while another connecting tube was used to collect the displaced water, which was thereafter measured. The $\mathrm{H}_{2}$ produced was dried using borax as a drying agent and then passed into a burner. The $\mathrm{H}_{2}$ was burnt using the burner for boiling water. The $\mathrm{H}_{2}$ produced could be used for domestic as well as industrial applications and can also be fed into a fuel cell to produce electricity. The experimental setup of this study and the schematic diagram are presented in Figures 1 and 2, respectively. Three replicates of the two sets of experiments were carried out with the average values reported in this study. 


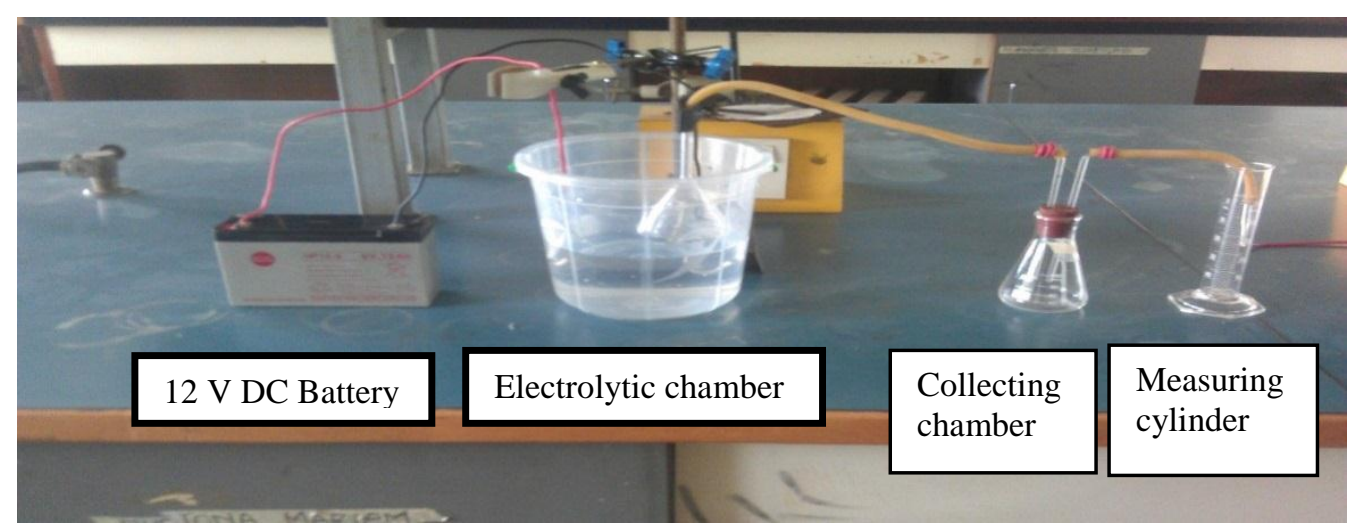

Figure 1 Pictorial view of experimental setup

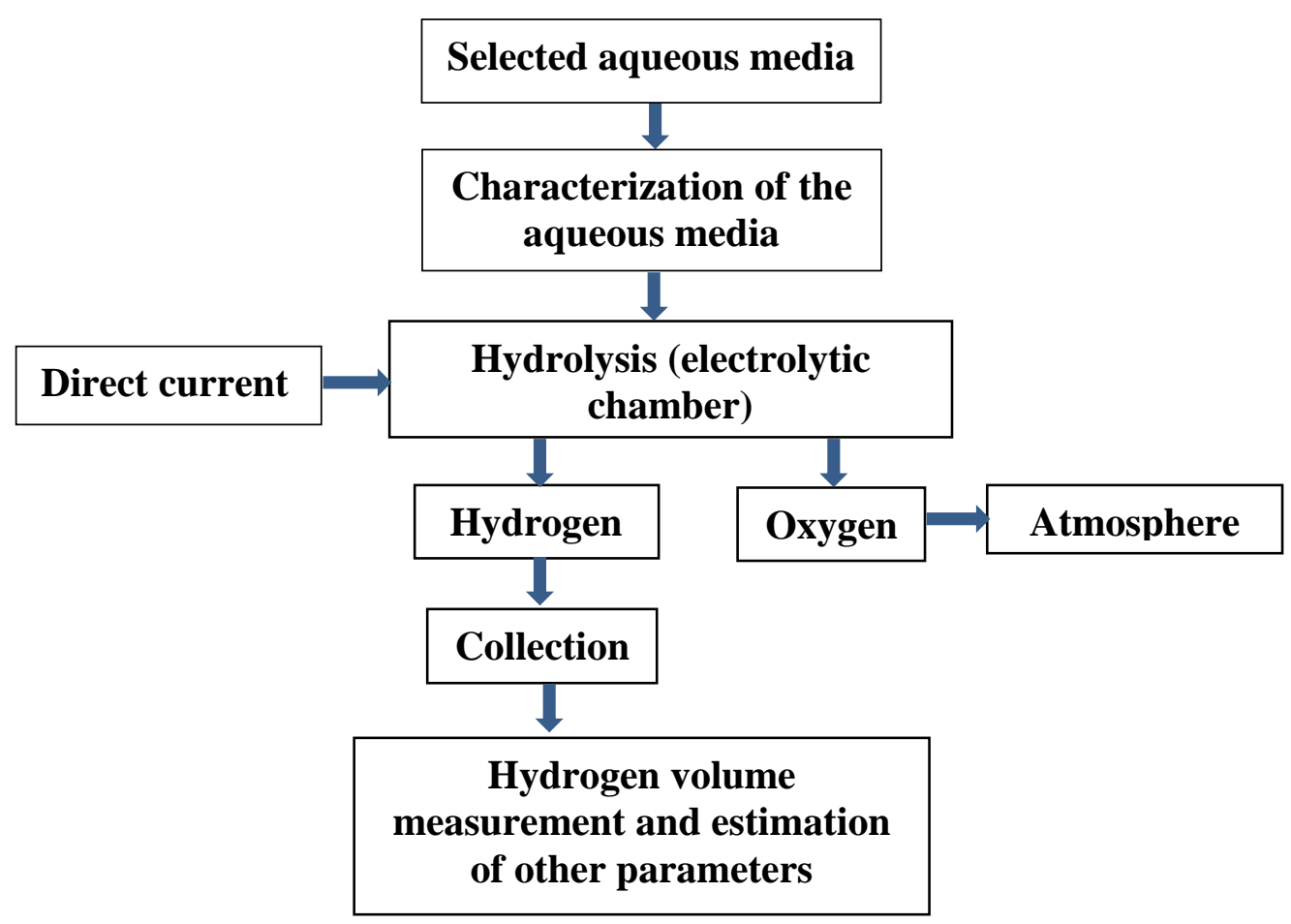

Figure 2 Schematic diagram of the study

\subsection{Hydrolysis Parameters}

The volume and flow rate of the $\mathrm{H}_{2}$ collected, the amount of current utilized and electric power consumed, and the effectiveness of the hydrolysis of all the AM were estimated using Equations 1-3. Also, the Faradic, thermal, and energy efficiencies were estimated using Equations 4-7 (Zeng \& Zhang, 2010).

$$
\begin{gathered}
Q_{V}\left(\frac{g}{h}\right)=\left(v\left(\mathrm{~cm}^{3}\right) \times \rho_{\text {hydrogen }}\left(\frac{g}{\mathrm{~cm}^{\mathrm{g}}}\right)\right) / t(h) \\
P_{a}(W)=V \times I \\
\varepsilon\left(\frac{\mathrm{kWh}}{g}\right)=0.5 P_{a} / 1000 Q_{V} \\
\eta_{\text {energy }}=\frac{283.8(\mathrm{k} /)}{V I t} \\
\eta_{\text {faradic }}=\frac{1.23}{E_{\text {cell }}}
\end{gathered}
$$




$$
\eta_{\text {thermal }}=\frac{1.48}{E_{\text {cell }}}
$$

where $Q_{V}$ is the flow rate of $\mathrm{H}_{2}$ produced $(\mathrm{g} / \mathrm{h}) ; v$ is the test tube volume $\left(\mathrm{cm}^{3}\right) ; t$ is the time taken (h); $\rho_{\text {hydrogen }}$ is the density of $\mathrm{H}_{2}\left(0.00008988 \mathrm{~g} / \mathrm{cm}^{3}\right) ; P_{\alpha}$ is the power of electrolyzer (W); $V$ is the voltage $(\mathrm{V}) ; I$ is the current $(\mathrm{A}) ; \varepsilon$ is the effectiveness of electrolysis $(\mathrm{kWh} / \mathrm{g}) ; \eta_{\text {energy }}$ is the energy efficiency at $25^{\circ} \mathrm{C}$; $\eta_{\text {faradic }}$ is the Faradic efficiency at $25^{\circ} \mathrm{C} ; \eta_{\text {thermal }}$ is the thermal efficiency.

\section{RESULTS AND DISCUSSION}

\subsection{Preliminary Study}

A preliminary study was carried out in order to provide an overview of the main study. A glowing splint introduced to the gas obtained at the cathode $\left(\mathrm{H}_{2}\right)$ burned with a pale blue flame and made an explosive sound. This confirmed that $\mathrm{H}_{2}$ was produced at the cathode.

\subsection{Characterization of Aqueous Media}

The AM from various sources selected for this study were characterized by their $\mathrm{pH}$, resistivity, and salinity. The $\mathrm{pH}$, salinity, and resistivity were measured before their hydrolysis and without the addition of $\mathrm{NaCl}$, while only $\mathrm{pH}$ was determined after the addition of $\mathrm{NaCl}$. Table 1 presents the aforementioned properties for the AM used in this study.

\subsection{1. $\mathrm{pH}$ value}

The $\mathrm{pH}$ is a measure of the acidity or alkalinity of solutions on a scale from 1 to 14 , with ultrapure water possessing a neutral $\mathrm{pH}$ of 7.0. The $\mathrm{pH}$ of the AM before and after the addition of $\mathrm{NaCl}$ is provided in Table 1. Prior to the addition of $\mathrm{NaCl}, \mathrm{FW}$, urine, $\mathrm{ROW}$, and $\mathrm{TW}$ were found to be acidic, with a $\mathrm{pH}$ value of less than 7; while DIW and SW were alkaline, with $\mathrm{pH}$ values above 7. Of all the measured AM, FW was the most acidic, with a $\mathrm{pH}$ value of 5.09; while the most basic $\mathrm{AM}$ was $\mathrm{SW}(\mathrm{pH}=7.92)$. After the addition of $\mathrm{NaCl}$, only two of the four acidic media were found to have $\mathrm{pH}$ values in the acidic region. As seen in Table $1, \mathrm{FE}(\mathrm{pH}=$ 5.12) and urine $(\mathrm{pH}=6.4)$ are the only acidic $\mathrm{AM}$, while the rest reside in the basic region, with $\mathrm{pH}$ values above 7. Of the AM used in this study, SW had the high alkalinity, followed by DIW, ROW, tap water, urine, and FE. The change in $\mathrm{pH}$ was observed to be significant for ROW (0.4) and urine (0.2), while the rest witnessed slight changes (0.02-0.03) in pH. Generally, the $\mathrm{pH}$ of all the $\mathrm{AM}$ was changed by the dissolution of $\mathrm{NaCl}$ into them. It can be observed (Table 1) that only SW had a $\mathrm{pH}$ higher than the control aqueous medium (DIW), which may be attributed to the presence of salts in sea water.

Table 1 Properties of aqueous media from various sources

\begin{tabular}{lccccc}
\hline & \multicolumn{2}{c}{ Before adding salt } & \multicolumn{2}{c}{ After adding salt } & \multirow{2}{*}{ Liquids } \\
\cline { 2 - 5 } & $\mathrm{pH}$ & Resistivity $(\mathrm{M} \Omega / \mathrm{cm})$ & Salinity $(\mathrm{mg} / \mathrm{l})$ & $\mathrm{pH}$ & \\
\hline DIW & 7.42 & 4.20 & 0.01 & 7.44 & 0.02 \\
FE & 5.09 & 4.56 & 10.01 & 5.12 & 0.03 \\
SW & 7.92 & 110.10 & 31.20 & 7.95 & 0.03 \\
Urine & 6.20 & 50.20 & 25.20 & 6.40 & 0.20 \\
ROW & 6.70 & 6.20 & 21.10 & 7.10 & 0.40 \\
TW & 6.99 & 5.00 & 11.20 & 7.01 & 0.02 \\
\hline
\end{tabular}

\subsubsection{Salinity}

Salinity refers to the concentration of dissolved salts in water, measured in terms of total dissolved salts (TDS) per unit of $\mathrm{mg} / \mathrm{l}$. The salinity of DIW was found to be $0.01 \mathrm{mg} / \mathrm{l}$, which is the smallest value of salinity measured for this study (see Table 1). This result implies that DIW 
contains as little as $0.01 \mathrm{mg}$ of dissolved salt per litre, which can be attributed to the fact that the water has been demineralized. It can be observed in Table 1 that SW had the highest salinity $(31.2 \mathrm{mg} / \mathrm{l})$, followed by urine $(25.2 \mathrm{mg} / \mathrm{l})$, ROW (21.1 mg/l), TW (11.2 mg/l), and FE (10.1 $\mathrm{mg} / \mathrm{l})$. It can be deduced from these results that the level of salinity of the AM can be linked to the mineral contents present in them. For instance, the mineral contents found in FE include phosphate ions, chloride, and magnesium, which would have been dissolved into the water during the fufu sieving process. Also, the dissolution of chloride, fluoride, and other compounds in TW and ROW, and the dissolution of chloride, magnesium, and potassium ions found in urine, can be attributed to their level of salinity. In the present study, the salinity of SW was the highest (31.2 mg/l compared to other AM). In addition, sodium and chlorine ions are the predominant ions in sea water, and the concentrations of magnesium, calcium, and sulphate are also substantial.

\subsubsection{Resistivity}

Resistivity is the electrical resistance of a conductor of unit cross-sectional area and unit length, and is used to compare the ability of various materials to conduct electricity. In this study, resistivity is a measurement of the opposition of AM to the flow of a current over distance. Pure water has been reported to have a resistance of $18.2 \mathrm{M} \Omega \mathrm{cm}$ (Bevilacqua, 1998). From Table 1, it can be observed that SW and DIW have the highest and lowest resistivity- $110.10 \mathrm{M} \Omega \mathrm{cm}$ and $4.2 \mathrm{M} \Omega \mathrm{cm}$, respectively. It can also be seen that the control medium has the lowest resistivity due to its relative lack of minerals, while SW has the highest resistivity because of its high mineral content. It is evident that the higher the salinity of the aqueous medium, the greater its ability to resist the flow of current through it (Table 1). The measured resistivity of the AM was highest for sea water, followed by urine, ROW, tap water, FE, and DIW.

\subsection{Hydrogen Production Parameters}

\subsubsection{Volume of hydrogen collected}

The volume of $\mathrm{H}_{2}$ liberated during hydrolysis of the various $\mathrm{AM}$ with and without dissolution of $\mathrm{NaCl}$ is shown in Figure 3. In the first set of experiments (without $\mathrm{NaCl}$ ), it was observed that urine, $\mathrm{SW}$, and $\mathrm{FE}$ released the most $\mathrm{H}_{2}$, with values of $2.0,1.9$, and $1.3 \mathrm{~cm}^{3}$, respectively. DIW produced the lowest volume of $\mathrm{H}_{2}\left(0.1 \mathrm{~cm}^{3}\right)$. These results may be adduced to the chemical composition and mineral content of these AM, with DIW being demineralized. The second set of experiments was characterized by the dissolution of $\mathrm{NaCl}$ in the $\mathrm{AM}$, and the quantities of $\mathrm{H}_{2}$ produced are presented in Figure 3.

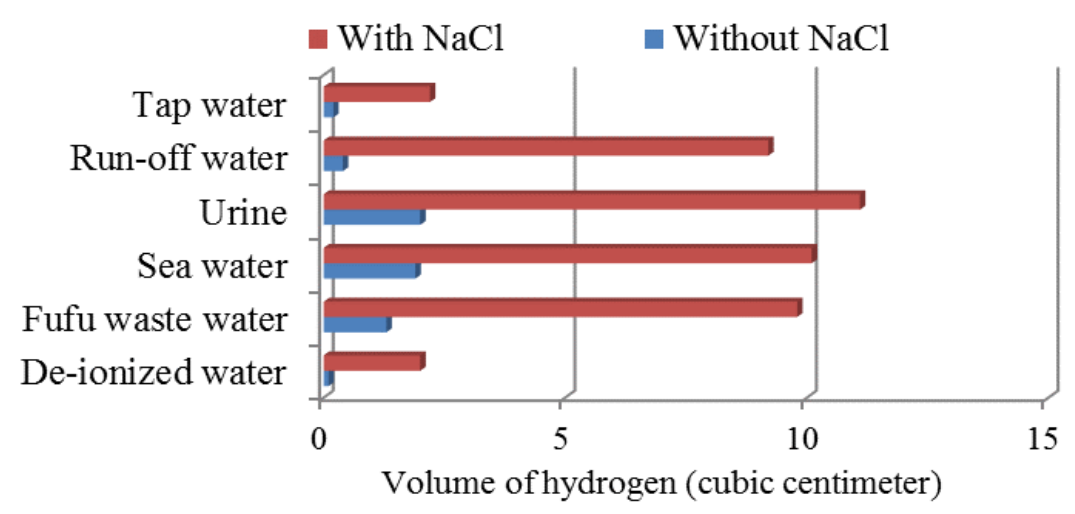

Figure 3 Volume of hydrogen produced during hydrolysis

SW, urine, FE, and ROW yielded high volumes of $10.1,11.1,9.8$, and $9.2 \mathrm{~cm}^{3}$, respectively; while volumes of 2.0 and $2.2 \mathrm{~cm}^{3}$ were recorded for DIW and TW, respectively. These results demonstrate a considerable increase in the volume of $\mathrm{H} 2$ liberated for all the AM due to the 
addition of $\mathrm{NaCl}$. From Figure 3, ROW exhibited the most significant change (from $0.4 \mathrm{~cm} 3$ to $9.2 \mathrm{~cm}^{3}$ ) in $\mathrm{H}_{2}$ volume as a result of the dissolution of $\mathrm{NaCl}$. This was closely followed by ROW $\left(8.8 \mathrm{~cm}^{3}\right), \mathrm{FE}\left(8.5 \mathrm{~cm}^{3}\right)$, and SW $\left(8.2 \mathrm{~cm}^{3}\right)$. However, DIW yielded the smallest change $\left(1.9 \mathrm{~cm}^{3}\right)$ in $\mathrm{H}_{2}$ volume, slightly less than that of TW $\left(2 \mathrm{~cm}^{3}\right)$. This may be connected to the presence of ions in TW, as the same $\mathrm{pH}$ difference $(0.2)$ was recorded for both AM (see Table 1). Apparently, the salinity, resistivity, and $\mathrm{pH}$ values of the AM earlier reported under subsection 3.2 were found to influence the volume of $\mathrm{H}^{2}$ produced.

\subsubsection{Flow rate of hydrogen liberated}

The flow rates of $\mathrm{H}_{2}$ produced from the AM are presented in Figure 4. These values were estimated using Equation 1. Flow rates of $\mathrm{H}_{2}$ from the hydrolysis of DIW, FE, SW, urine, ROW, and TW without the addition of $\mathrm{NaCl}$ were $0.032,0.421,0.615,0.647,0.129$, and 0.065 $\mathrm{g} / \mathrm{h}$, respectively. It can be observed that the same pattern exists in both Figures 3 and 4 . This is because a linear relationship exists between the two parameters. Also, the flow rates of 0.647 , 3.171, 3.268, 3.592, 2.977, and $0.712 \mathrm{~g} / \mathrm{h}$ were estimated for DIW, FE, SW, urine, ROW, and TW, respectively. Under the two sets of experiments, urine had the highest flow rate while DIW had the lowest. From Figure 4, it is apparent that the dissolution of $\mathrm{NaCl}$ in the media increased the flow rate of $\mathrm{H}_{2}$ production. The flow rates (without $\mathrm{NaCl}$ addition) of three of the $\mathrm{AM}$ (FE, SW, and urine) investigated were found to be in agreement with previous studies, which reported $0.33 \mathrm{~g} / \mathrm{h}$ (urine) and $0.78 \mathrm{~g} / \mathrm{h}$ (industrial wastewater) (Abdel-Monem et al., 2013; Mahmoud et al., 2013). Also, the $\mathrm{H}_{2}$ flow rates of TW, urine, and $\mathrm{FE}$ on dissolution with $\mathrm{NaCl}$ as obtained in this study were found to be considerably higher than those reported in a previous work (Slama, 2013). In addition, the flow rates of $\mathrm{H}_{2}$ (with and without $\mathrm{NaCl}$ ) as achieved here were within the range of $\mathrm{H}_{2}$ flow rates $(0.0749-11.68 \mathrm{~g} / \mathrm{h})$ reported in the literature, except for DIW and TW without $\mathrm{NaCl}$ dissolution (Call \& Logan, 2008).

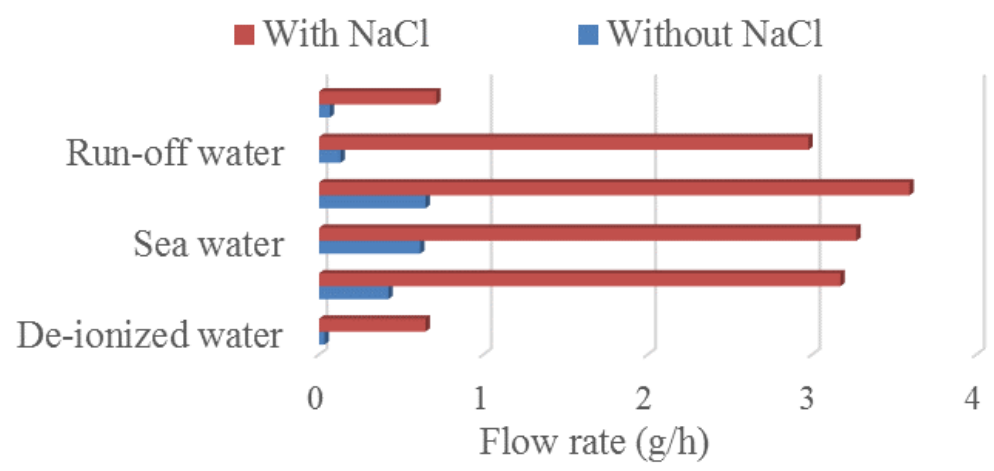

Figure 4 Flow rate of hydrogen produced during hydrolysis

\subsubsection{Current utilized}

An illustration of the amount of current involved in the hydrolysis (with or without dissolution of $\mathrm{NaCl}$ ) of the various $\mathrm{AM}$ is provided in Figure 5. It can be observed that without the dissolution of $\mathrm{NaCl}, 0.03,0.04,0.18,0.2,0.04$, and 0.04 Ampere (A) were utilized for the hydrolysis of DIW, FE, SW, urine, ROW, and TW, respectively. Urine $(0.2 \mathrm{~A})$ and SW $(0.18$ A) demonstrated a relatively high current compared to the other AM, in the range of 0.03-0.04 A. As expected, the quantity of current used during hydrolysis increased when $\mathrm{NaCl}$ was dissolved into the AM. The values of 0.2, 0.21, 0.93, 0.87, 0.24, and 0.21 A were measured for the hydrolysis of DIW, FE, SW, urine, ROW, and TW, respectively, when $\mathrm{NaCl}$ was dissolved within them. Urine and SW were expected to provide high resistance to current flow due to their relatively high resistivity, as evident in their consumption of more current during hydrolysis than other AM. 


\subsubsection{Electric power consumed}

Figure 6 shows the power consumed during the hydrolysis of the AM. For the first set of experiments, the power consumed by the hydrolysis of DIW, FE, SW, urine, ROW, and TW was $0.3,1.0,2.2,2.4,0.8$, and $0.5 \mathrm{~W}$, respectively. These values can be attributed to the level of resistance of the AM to the flow of current, which is due to the chemical composition of the AM. It can also be seen that the hydrolysis of the DIW consumed the lowest power $(0.3 \mathrm{~W})$, while urine hydrolysis consumed the most power $(2.4 \mathrm{~W})$. With the dissolution of $\mathrm{NaCl}$ into the AM, the power consumed during hydrolysis was determined to be $2.4 \mathrm{~W}$ (DIW), $5.5 \mathrm{~W}$ (FE), 10.4 W (SW), 11.2 W (urine), $4.4 \mathrm{~W}$ (ROW), and 2.5 W (TW). These values demonstrated a considerable increase when compared to those obtained without the addition of $\mathrm{NaCl}$. Urine and SW showed a significant change of 8.8 and $8.2 \mathrm{~W}$, respectively, which can be linked to their considerably high resistivity and moderately high salinity (see Table 1 ). The power consumed for the production of $\mathrm{H}_{2}$ from $\mathrm{TW}$, urine, and $\mathrm{FE}$ after the dissolution of $\mathrm{NaCl}$ was moderately lower than reported in an earlier study (Slama, 2013).

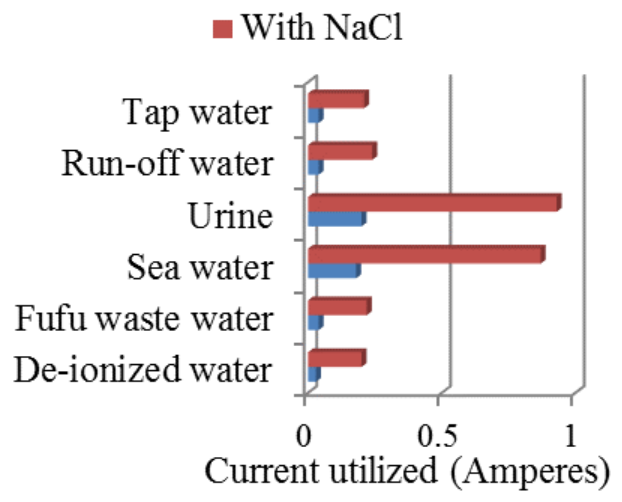

Figure 5 Current utilized during hydrolysis

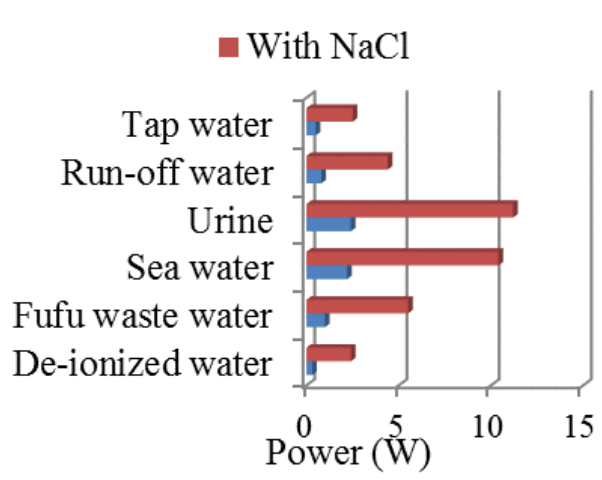

Figure 6 Power consumed during hydrolysis

\subsubsection{Effectiveness of hydrolysis}

In relation to this study, effectiveness is the ratio of the power consumed during hydrolysis of the AM to the volume of $\mathrm{H}_{2}$ produced. The effectiveness of the hydrolysis of the AM was estimated using Equation 3 and the results are shown in Figure 7. For the first set of experiments, DIW was observed to have the highest value of effectiveness $(20.23 \mathrm{kWh} / \mathrm{g})$, closely followed by TW (13.35 kWh/g), urine and ROW $(6.68 \mathrm{kWh} / \mathrm{g}), \mathrm{SW}(6.32 \mathrm{kWh} / \mathrm{g})$, and lastly, FE $(2.05 \mathrm{kWh} / \mathrm{g})$. The high values of effectiveness estimated for DIW and TW were due to the production of a low volume of $\mathrm{H}_{2}$ from low power consumption (Figures 3 and 6). The high power consumed in the production of a high volume of $\mathrm{H}_{2}$ was responsible for the moderate values of effectiveness for SW, urine, and ROW. However, FE recorded the lowest value of effectiveness $(2.05 \mathrm{kWh} / \mathrm{g})$ because this medium produced a relatively high volume of $\mathrm{H}_{2}$ with moderate power consumption. For the experiment involving the addition of $\mathrm{NaCl}$ into the AM, the effectiveness of DIW, FE, SW, urine, ROW, and TW was 6.68, 1.63, 5.75, 5.59, 1.52 , and $6.07 \mathrm{kWh} / \mathrm{g}$, respectively. The same pattern of effectiveness can be seen for the two experiments, except in the case of ROW. The low effectiveness value of ROW is due to the fact that the addition of $\mathrm{NaCl}$ has the highest effect on this medium in the production of $\mathrm{H}_{2}$, as mentioned earlier (see Figure 3). The power consumption achieved in this study is considerably lower than the $11 \mathrm{kWh} / \mathrm{g}$ (industrial wastewater) and $196 \mathrm{kWh} / \mathrm{g}$ (urine) reported in previous studies (Abdel-Monem et al., 2013; Mahmoud et al., 2013) and may be due to the lower power consumption coupled with increased $\mathrm{H}_{2}$ production demonstrated in this work.

\subsubsection{Hydrogen production efficiencies}

The energy efficiency of $\mathrm{H}_{2}$ production for each medium was estimated using Equation 4 and is 
provided in Figure 8. It can be observed that higher energy efficiencies were achieved for DIW (0.066 and 0.438), FE (0.055 and 0.328), ROW (0.063 and 0.328), and TW (0.066 and 0.328) compared to those of SW (0.015 and 0.073) and urine (0.014 and 0.066) with and without $\mathrm{NaCl}$ dissolution in the media. These values are generally low because $\mathrm{H}_{2}$ production was carried out in this study for 30 mins and a longer duration would likely increase $\mathrm{H}_{2}$ yield.

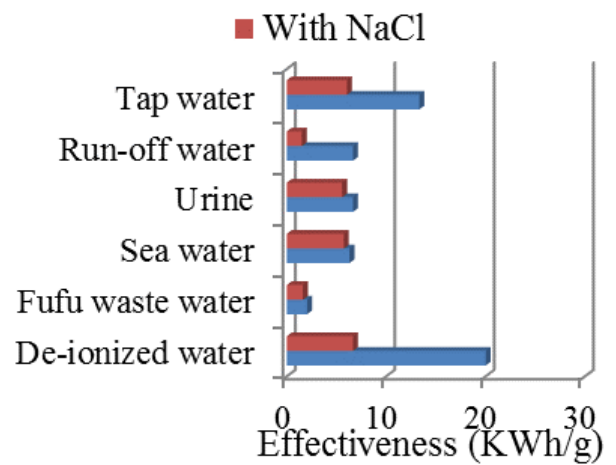

Figure 7 Effectiveness of hydrolysis

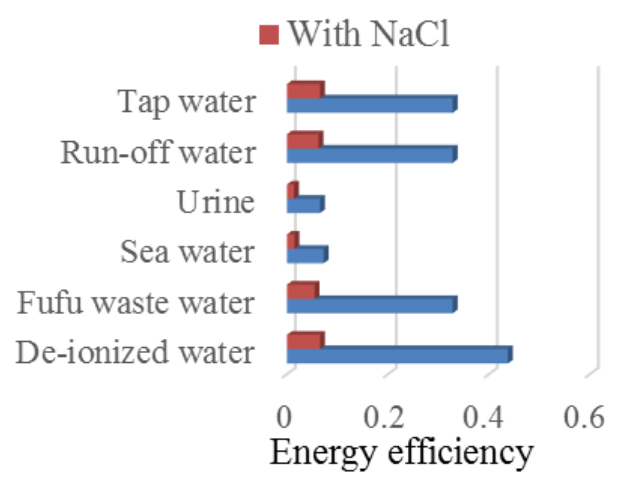

Figure 8 Energy efficiency of aqueous media

The energy efficiencies were found to be substantially higher without the addition of $\mathrm{NaCl}$, which can be attributed to the dissolution of $\mathrm{NaCl}$ in the media, in turn lowering the activation energy and, subsequently, reducing the energy efficiency by increasing both current and power consumed during hydrolysis. It is pertinent to note that the energy efficiencies reported here did not take into consideration the volume of $\mathrm{H}_{2}$ produced by each medium, as is the case with effectiveness.

Faradic efficiency ( $\mu_{\text {Faradic }}$ ) expressed in percent is the theoretical energy required to break water molecules in the actual cell voltage. It is also a measure of cell efficiency considering cell voltage. In this study, the $\mu_{\text {Faradic }}$ calculated using Equation 5 was $10.25 \%$ at $25^{\circ} \mathrm{C}$. The Faradic efficiency obtained in this work was less than $100 \%$ since there were losses in the cell during the hydrolysis; this outcome is in agreement with the literature (Zeng \& Zhang, 2010). Thermal efficiency $\left(\mu_{\text {thermal }}\right)$ is a definite energy input in the actual cell voltage expressed in percentage. Moreover, it is the additional cell voltage above the reversible voltage required to maintain the thermal balance. The thermal efficiency of the hydrolysis of the AM was estimated to be $12.33 \%$ (at $25^{\circ} \mathrm{C}$ ). Since the hydrolysis is exothermic in nature, it is expected that the thermal efficiency would be less than $100 \%$ as heat would be lost to the environment. Comparison of this work with a previous study (which used microbial electrolysis cells for $\mathrm{H}_{2}$ production) showed that the thermal efficiency for the production of $\mathrm{H}_{2}$ from $\mathrm{TW}$ and $\mathrm{FE}$ on dissolution with $\mathrm{NaCl}$ was slightly higher, whereas the thermal efficiency for urine was slightly lower (Slama, 2013). However, the use of microbial electrolysis cells has been reported to have higher efficiency than traditional electrolysis (Call \& Logan, 2008).

\subsection{Statistical Analysis of Parameters}

A $t$-test was conducted on the data (volume of $\mathrm{H}_{2}$ produced, current and power consumed, and effectiveness) obtained in this study. The purpose of the $t$-test was to check the significance of the dissolution of $\mathrm{NaCl}$ into the $\mathrm{AM}$ during hydrolysis. Correlation coefficients and $p$-values of 0.827 and $0.006,0.340$ and $0.053,0.999$ and $0.024,0.997$ and 0.012 , and 0.340 and 0.053 were obtained for the volume of $\mathrm{H}_{2}$, the flow rate of $\mathrm{H}_{2}$, the current utilized, the power consumed, and effectiveness, respectively. These results showed that the dissolution of $\mathrm{NaCl}$ into the $\mathrm{AM}$ was significant, as evident in the $p$-values, except for the flow rate of $\mathrm{H}_{2}$ and effectiveness. Also, positive and strong relationships existed between the data (hydrolysis with and without $\mathrm{NaCl}$ dissolution) for all the parameters except effectiveness. In considering the data garnered 
from the two sets of experiments, the $t$-test showed that $t_{\text {critcal }}(2.0452)<t_{\text {observed }}(4.1139)$ with a $p$-value of 0.0032 at $95 \%$ confidence interval and a correlation coefficient of 0.8507 . This revealed that the obtained hydrolysis data (with and without dissolution of $\mathrm{NaCl}$ ) were statistically dissimilar, which further supports the significance of $\mathrm{NaCl}$ dissolution in $\mathrm{AM}$ in the production of $\mathrm{H}_{2}$.

\section{CONCLUSION}

This study presented the feasibility of $\mathrm{H}_{2}$ production from $\mathrm{AM}$ via hydrolysis. Two sets of experiments were conducted with and without the dissolution of $\mathrm{NaCl}$ in the AM. Of all the $\mathrm{AM}$ hydrolyzed, with or without $\mathrm{NaCl}$ dissolution, urine, $\mathrm{SW}$, ROW, and $\mathrm{FE}$ yielded a relatively high volume of $\mathrm{H}_{2}$ compared to the other AM. It can be seen from the resulting trend that both the salinity and resistivity of the AM influenced the volume and flow rate, current, and power consumed. In terms of effectiveness for hydrolysis carried out without the dissolution of $\mathrm{NaCl}, \mathrm{FE}, \mathrm{SW}$, and urine yielded relatively high values, whereas ROW, FE, SW, and urine gave higher values when $\mathrm{NaCl}$ was dissolved within them. The $t$-test carried out on the obtained data demonstrated the significance ( $p$-value $=0.00032$ ) of $\mathrm{NaCl}$ dissolution in the AM. This study revealed the possibility of using ROW and FE (which constitutes an environmental nuisance) as an $\mathrm{H}_{2}$ production source outside the use of $\mathrm{SW}$ and urine.

\section{ACKNOWLEDGMENT}

The immeasurable contributions of colleagues in the Department of Agricultural and Mechanical Engineering, College of Engineering and Environmental Studies, of Olabisi Onabanjo University, Ibogun Campus, toward the success of this study are highly appreciated.

\section{REFERENCES}

Abdel-Monem, N.M., Abdel-Salam, O.E., Nassar, A.F., Mahmoud, M.H., 2013. Oxidation of Urea in Human Urine using Flow-by Porous Graphite Electrode. International Journal of Scientific \& Engineering Research, Volume 4, pp. 1715-1723

Aggarwal, N., Goyal, K., Narang, S., 2013. Road Transport System Run by Hydrogen as a Fuel Generated through Urine. International Journal for Advance Research in Engineering and Technology, Volume 1, pp. 16-19

Amoo, L.M., Fagbenle, R.L., 2014. An Integrated Impact Assessment of Hydrogen as a Future Energy Carrier in Nigeria's Transportation, Energy and Power Sector. International Journal of Hydrogen Energy, Volume 39, pp. 12409-12433

Bevilacqua, A.C., 1998. Ultrapure Water - The Standard for Resistivity Measurements of Ultrapure Water. Available online at https://www.snowpure.com/docs/thornton-upwresistivity-measurement.pdf, Accessed on December 2, 2016

Boggs, B.K., Rebecca, L.K., Botte, G.G., 2009. Urea Electrolysis: Direct Hydrogen Production from Urine. Chemical Communication, pp. 4859-4861

Bouazizi, N., Slama, R.B., Bargougui, R., Lazhar, L., Natija, B., 2014. Hydrogen Production by Electrolysis of Water: Factors with an Influence on the Corrosion. Global Journal of Science Frontier Research, Volume 14, pp. 46-56

Call, D., Logan, B.E., 2008. Hydrogen Production in a Single Chamber Microbial Electrolysis Cell Lacking a Membrane. Environmental Science Technology, Volume 42, pp. 3401-3406

Giwa, S.O., Chuah, L.A., Adam, N. M., 2010. Investigating "Egusi" (Citrullus Colocynthis L.) Seed Oil as Potential Biodiesel Feedstock. Energies, Volume 3, pp. 607-618

Holladay, J.D., Hu, J., King, D.L., Wang, Y., 2009. An Overview of Hydrogen Production Technologies. Catalysis Today, Volume 139, pp. 244-260 
Luo, N.J, Jiang, Z., Shi, H.H., Cao, F.H., Xiao, T.C., Edwards, P., 2009. Photocatalytic Conversion of Oxygenated Hydrocarbons to Hidrogen over Heteroatom-doped $\mathrm{TiO} 2$ Catalysts. J. Catal., Volume 34, pp. 125-129

Mahmoud, M.H., Abdel-Salam, O.E., Abdel-Monem, N.M., Nassar, A.F., El-Halwany, M.A., 2013. Removal of Urea from Industrial Wastewater using Electro-Chemical Decomposition. Life Science Journal, Volume 10, pp. 2048-2055

Nasruddin, S., Kosasih, E.A., Kurniawan B., Supriyadi, Zulkarnain I.A., 2016a. Optimization of Hydrogen Storage Capacity by Physical Adsorption on Open-Ended Single-Walled Carbon Nanotube as Diameter Function. International Journal of Technology, Volume 7(2), pp. 264-273

Nasruddin, S., Kosasih, E.A., Kurniawan B., Supriyadi, Zulkarnain I.A., 2016b. Improving Hydrogen Physisorption Energy using SWCNTS Through Structure Optimization and Metal Doping Substitution. International Journal of Technology, Volume 7(8), pp. 14551463

Ni, M., Leung, M.K.H., Leung, D.Y.C., 2006. Prospect of Solid Oxide Steam Electrolysis for Hydrogen Production. In: Proceeding of The World Hydrogen Energy Conference, Lyon, June, pp. 13-16

Saksono, N., Seratri, R.T., Muthia, R., Bismo, S., 2015. Phenol Degradation in Wastewater with a Contact Glow Discharge Electrolysis Reactor using a Sodium Sulfate. International Journal of Technology, Volume 6(7), pp. 1153-1163

Slama, R.B., 2013. Production of Hydrogen by Electrolysis of Water: Effects of the Electrolyte Type on the Electrolysis Performances. Computational Water, Energy, and Environmental Engineering, Volume 2, pp. 54-58

Slamet, Kusrini, E., Afrozi, A.S., Ibadurrohman, M., 2015. Photocatalytic Hydrogen Production from Glycerol-Water Over Metal Loaded and Non-Metal Doped Titanium Oxide. International Journal of Technology, Volume 6(4), pp. 520-532

Wang, G., Ling, Y., Lu, X., Wang, H., Qian, F., Tong, Y., Li Y., 2012. Solar Driven Hydrogen Releasing from Urea and Human Urine. Energy and Environmental Science, Volume 5, pp. 8215-8219

Zeng, K., Zhang, D., 2010. Recent Progress in Alkaline Water Electrolysis for Hydrogen Production and Applications. Progress in Energy and Combustion Science, Volume 36, pp. $307-326$ 